\section{A Novel Computer-Aided Method to Evaluate Scoliosis Curvature using Polynomial Math Function}

\author{
Guamán-Lozada D. F.*® , Cabrera-Escobar J.², Guamán- \\ Lozada M. D. ${ }^{3}$, Romero-Rodríguez V. ${ }^{4}$, Castro-Martin A. P. ${ }^{5}$, \\ Romero-Rodríguez M. G. ${ }^{6}$, Ying-Ying H.7, Zhi-Han Y. ${ }^{8}$, Jia- \\ Wei $\mathrm{H}^{8}{ }^{8}$
}

\begin{abstract}
Background: Scoliosis is a health problem that causes a side-to-side curvature in the spine. The curvature may have an "S" or "C" shape. To evaluate scoliosis, the Cobb angle has been commonly used. However, digital image processing allows the Cobb angle to be obtained easily and quickly, several researchers have determined that Cobb angle contains high variations (errors) in the measurements. Therefore, a more reproducible computer aided-method to evaluate scoliosis is presented.
\end{abstract}

Material and Methods: In this analytical study, several polynomial curves were fitted to the spine curvature ( $4^{\text {th }}$ to $8^{\text {th }}$ order) of thirty plain films of scoliosis patients to obtain the Curvature-Length of the spine. Each plain film was evaluated by 3 physician observers. Curvature was measured twice using the Cobb method and the proposed Curvature-Length Technique (CLT). Data were analyzed by a pairedsample Student t-test and Pearson correlation method using SPSS Statistics 25.

Results: The curve of $7^{\text {th }}$ order polynomial had the best fit on the spine curvature and was also used for our proposed method (CLT) obtaining a significant positive correlation when compared to Cobb measurements $(\mathrm{r}=0.863, \mathrm{P}<0.001)$. The Intraclass Correlation (ICC) was between 0.863 and 0.948 for Cobb method and 0.974 to 0.984 for CLT method. In addition, mean measurement of the inter-observer COV (Coefficient of Variation) for Cobb method was of 0.185 , that was significantly greater than the obtained with CLT method of 0.155 , this means that CLT method is 16.2\% more repeatable than Cobb Method.

Conclusion: Based on results, it was concluded that CLT method is more reproducible than the Cobb method for measuring spinal curvature.

Citation: Guamán-Lozada D. F, Cabrera-Escobar J, Guamán-Lozada M. D, Romero-Rodríguez V, Castro-Martin A. P, Romero-Rodríguez M G, Ying-Ying H, Zhi-Han Y, Jia-Wei H. A Novel Computer-Aided Method to Evaluate Scoliosis Curvature using Polynomial Math Function. $J$ Biomed Phys Eng. 2019;9(5):517-524. https://doi.org/10.31661/jbpe.v0i0.1194.

\section{Keywords}

Scoliosis; Spinal Curvatures; Polynomial; Methods; Cobb-Angle

\section{Introduction}

$\mathrm{T}$ he standard measurements of scoliosis has been Cobb method for a while [1]. With computer-aided measurement, Cobb angle has shown an improved precision and reliability measurement [2-4]. Nevertheless, many researchers find that Cobb has a low level of reproducibility [5]. In another hand, some works attribute that the main source of error in Cobb angle is made by the definition of the upper
${ }^{1} \mathrm{MSc}$, Escuela Superior Politécnica del Chimborazo, Riobamba, Chim-

borazo, Ecuador

${ }^{2}$ MEng, Escuela Superior Politécnica del Chimborazo, Riobamba, Chim-

borazo, Ecuador

${ }^{3} \mathrm{MD}$, Hospital del

IESS "Guasmo Sur",

Guayaquil, Guayas,

Ecuador

${ }^{4}$ MEng, Universidad

Técnica de Ambato,

Ambato, Tungurahua,

Ecuador

${ }^{5} \mathrm{MSc}$, Independent

Researcher, Ambato,

Tungurahua, Ecuador

${ }^{6} \mathrm{MPT}$, Universidad Na-

cional del Chimborazo,

Riobamba, Chimborazo,

Ecuador

${ }^{7} \mathrm{PhD}$, The 2nd Af-

filiated Hospital \&Yuy-

ing Children's Hospital

of Wenzhou Medical

University, Wenzhou,

Zhejiang, China

${ }^{8} \mathrm{MD}$, The 2 nd Af-

filiated Hospital \&Yuy-

ing Children's Hospital

of Wenzhou Medical

University, Wenzhou,

Zhejiang, China

*Corresponding author:

D. F. Guamán-Lozada

Escuela Superior Poli-

técnica del Chimborazo,

Riobamba, Chimborazo,

Ecuador

E-mail: datronica@gmail.

com

Received: 3 June 2019

Accepted: 20 July 2019 
and lower end-plate vertebrae used to determine cobb angle $[3,6,7]$. Deviations of Cobb angles from different works are around 2 to 10 degrees, including the computer assistant measurements [5,7-9].

Technology has led us to improve the measurements using image processing combined with mathematical tools. Therefore, there exist several researches about the use of computation in order to automate the measure of Cobb angle in digital scoliosis plain films [10-14]. This work presents a new method (CLT) to measure scoliosis using image processing and mathematics tools. The new CLT method evaluates a deformation spine enhancing the reliability and reproducibility of scoliosis measurements.

\section{Material and Methods}

This analytical study was conducted as follows:

\section{a. Study Subject}

Thirty full-spine plain films (17 women and 13 men; 9-63 years of age; mean, 26.4 years) between February 2018 and December 2018 were diagnosed with scoliosis imaging in the Department of Radiology at second Affiliated Hospital, and also Wenzhou Medical College were enrolled in the study after providing informed written consent (for subjects under 18 from parent and/or legal guardian). All procedures were approved by the Medical Human Rights Committee of Wenzhou Hospital.

\section{b. Scoliosis Measurement Cobb Method}

To measure Cobb angle, the superior and inferior vertebra affected by scoliosis was located. Cobb angle is defined as the angle formed by the intersection between the projection of the end plate of the superior and inferior of the most tilted vertebra [15] (Figure 1).

\section{CLT Technique}

Using image processing toolbox from Matlab 2018b software, digital plain films were

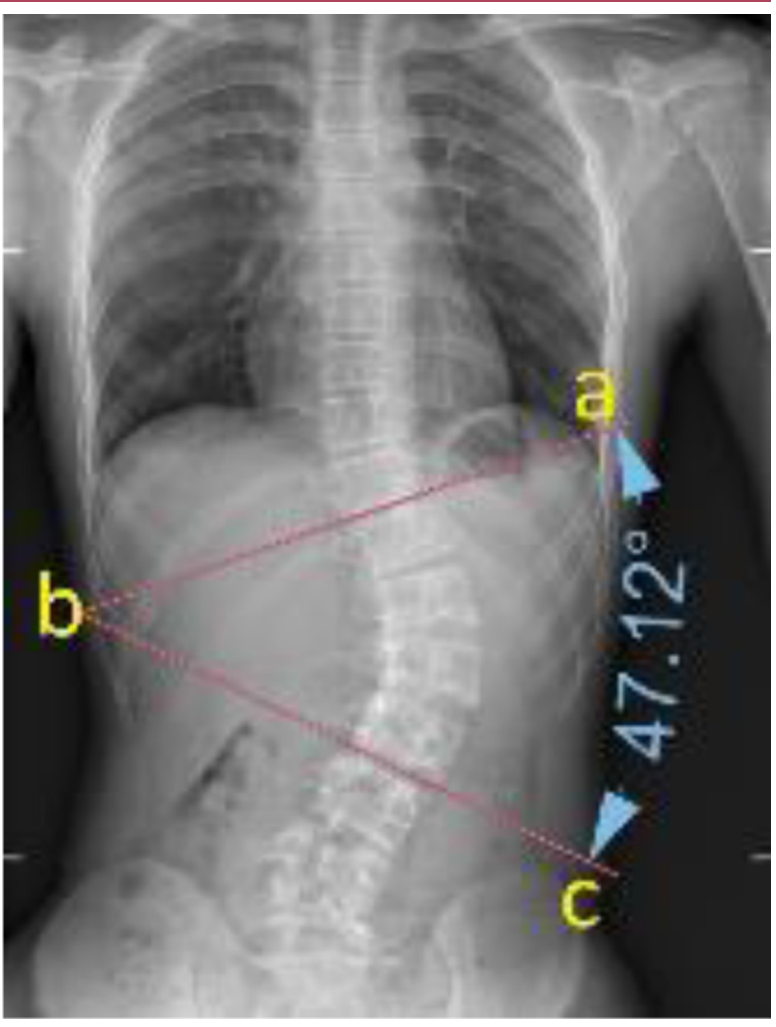

Figure 1: The angle forming at the vertex of the intersection of lines $a-b$ and $b-c$ which drawn parallel to the superior endplate of the superior vertebra and inferior endplate of the inferior vertebra respectively is the Cobb angle.

filtered (Figure 2) to emphasize the full-spine. Thus, that observers can easily locate approximate the centroid of each vertebra from $\mathrm{C} 7$ to L5 (Figure 3A), and the intersection(e) of two diagonals lines (a-b, c-d) from the corners of the vertebra is considered as the centroid [16] (Figure 3B).

Several polynomials ( $4^{\text {th }}$ to $8^{\text {th }}$ order) were used to fit a curve on the spine deformation. The polynomials were used to obtain the curve length of the spine based on the arclength equation (1). $7^{\text {th }}$ order polynomial equation was the one that obtained a better fit (Figure 4).

$$
s=\int_{a}^{b} \sqrt{1+\left(f^{\prime}(x)\right)^{2}}
$$




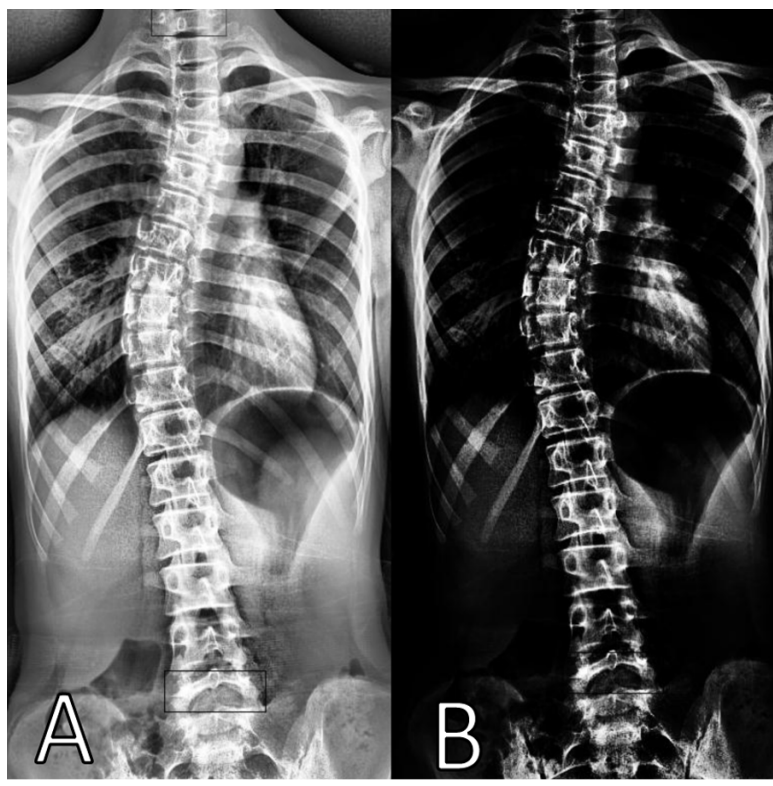

Figure 2: A. Image adjusted the contrast of the image using adaptive histogram equalization. B. Image adjusted the intensity to emphasize vertebras.



Figure 3: A. Approximate centroid localization of each vertebra from C7 to L5 B. the intersection of $a-b$ line with the $c-d$ line is considered as centroid (e).

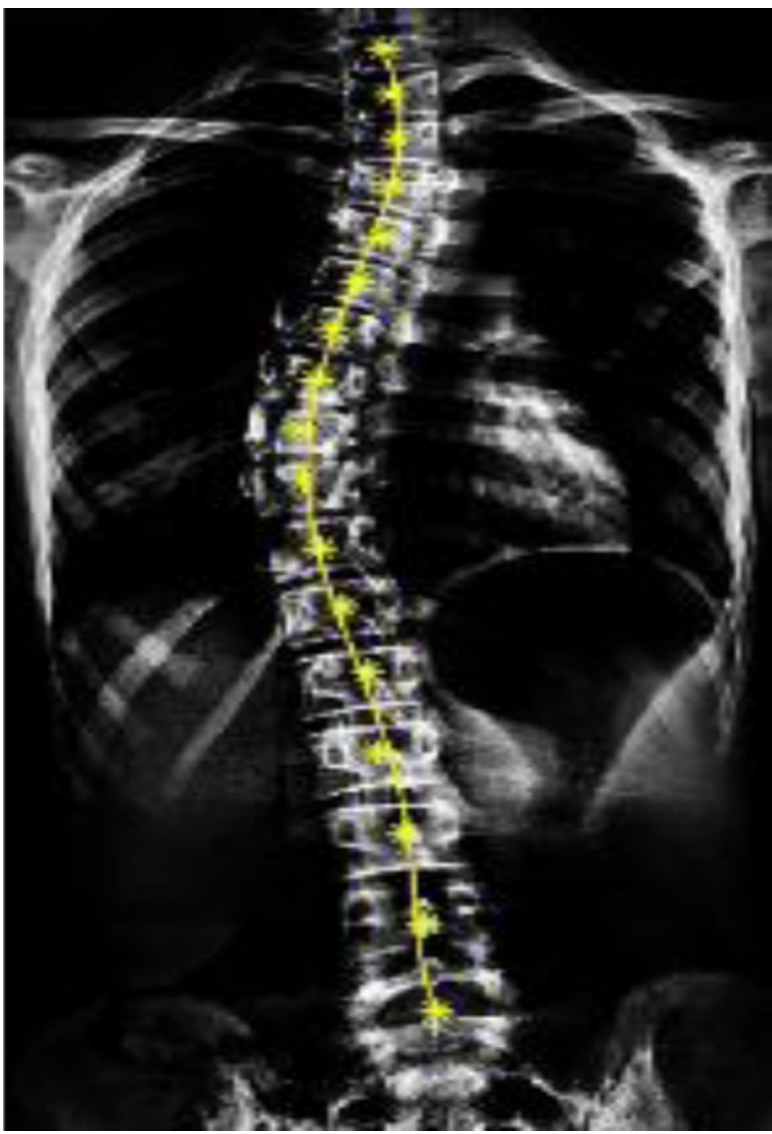

Figure 4: $7^{\text {th }}$ Order polynomial fitted on spine deformation

Where $s$ is the arc length; $a$ and $b$ are the locations of $\mathrm{C} 7$ and L5 vertebras, respectively, and $f^{\prime}(x)$ is the derivate of the polynomial curve.

Finally, the percent of deformation is obtained comparing the obtained curve length with the ideal spine length (Figure 5), which is the length in a straight line from the centroid of vertebra $\mathrm{C} 7$ to $\mathrm{L} 5$ by the equation (2).

$\%$ Error $=\frac{\text { Curvature Lenght }- \text { Ideal Lenght }}{\text { Ideal Lenght }} * 100$

\section{Measurement Design}

Three physicians with different experience levels were trained in both Cobb and CLT method to evaluate scoliosis. To measure Cobb and CLT angle, they used a graphical 


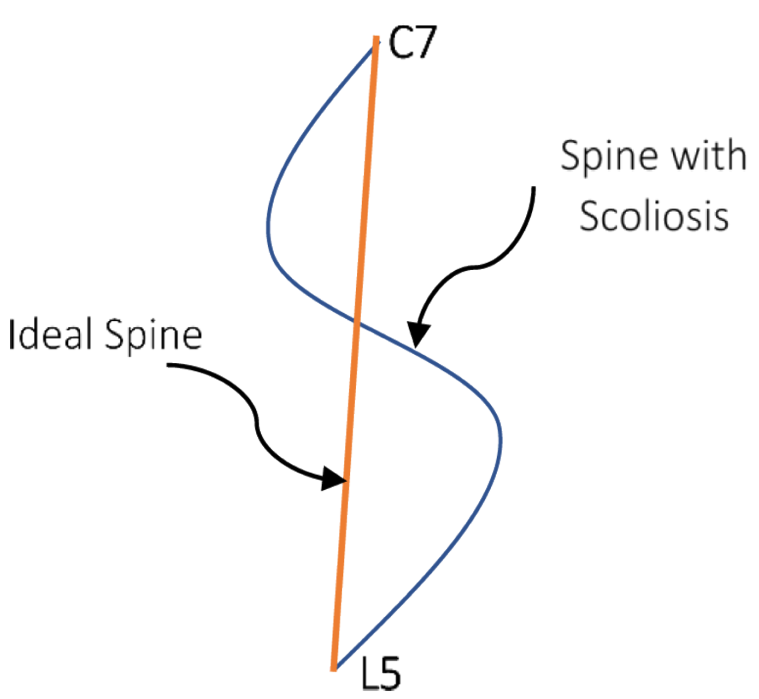

Figure 5: Ideal Spine vs a deformity spine (scoliosis).

design software (CorelDraw X8), and dedicated program developed in Matlab R2018b, respectively. Each physician measured twice each digital plain film after a 3-week interval. Physician 1 and 2 were an experienced traumatologist and a senior resident in a radiology department, respectively. In addition, physician 3 was an experienced internist.

\section{c. Statistical Analysis}

Intra-observer and inter-observer measurement values were analyzed used SPSS 25.0 software. Mean and the standard deviation of measurements were obtained from both Cobb and CLT measurement values. Those values were analyzed using the paired-sample Student t-test, and the correlation was found using the Pearson method.

\section{Results}

To measure reproducibility, a descriptive statistic was performed in the six measures (two per observer) of each radiography. Since the measures of the CLT and Cobb method are in percentage $(\%)$ and angles $\left({ }^{\circ}\right)$, respectively, the coefficient of variation (COV) was obtained for comparison. The mean, maximum and minimum standard deviations of the 30 plain radiographs measures are presented in Table 1.

Variations of the thirty radiography were

Table 1: Reproducibility resume $(n=30)$

\begin{tabular}{ccccc} 
& \multicolumn{2}{c}{ CLT } & \multicolumn{2}{c}{ COBB } \\
\cline { 2 - 5 } & STD (\%) & COV & STD $\left({ }^{\circ}\right)$ & COV \\
\hline Mean & 0.156 & 0.155 & 3.132 & 0.185 \\
\hline Max & 0.600 & 0.384 & 0.943 & 0.523 \\
\hline Min & 0.031 & 0.028 & 6.007 & 0.033
\end{tabular}

zeroed with the mean of the measurements of each one to evaluate the variation using the CLT method (Figure 6) and using the Cobb method (Figure 7).

In addition, to compare both methods, the $\mathrm{COV}$ of measurements of each radiography for CLT and COBB was plotted in Figure 8.

Results of intra-observer measurements done by three physicians using the Cobb method are shown in Table 2. A significant variation was computed by the measurements of the third physician $(p<0.005)$. In Table 3 , the results of the intra-observer measurements using CLT method are presented. There was no significant statistical variation in the measurements of the three measurements ( $p>0.005)$.

Tables 4 and 5 show results of inter-observer measurements using Cobb and CLT methods, respectively. With the Cobb method, measurements performed observer 1 are significantly different compared with observer 2 and 3 $(p<0.005)$. Results of measurement performed with the CLT method show that there is not any statistical difference in the variance between physician 1 and 3 . Therefore, it is demonstrated that the CLT method is superior that Cobb method.

The obtained Pearson correlation coefficient between the 30 measurements, calculated by Cobb method vs CLT method, was of 0.863 $(p<0.001)$. A scatterplot is shown in Figure 9. 


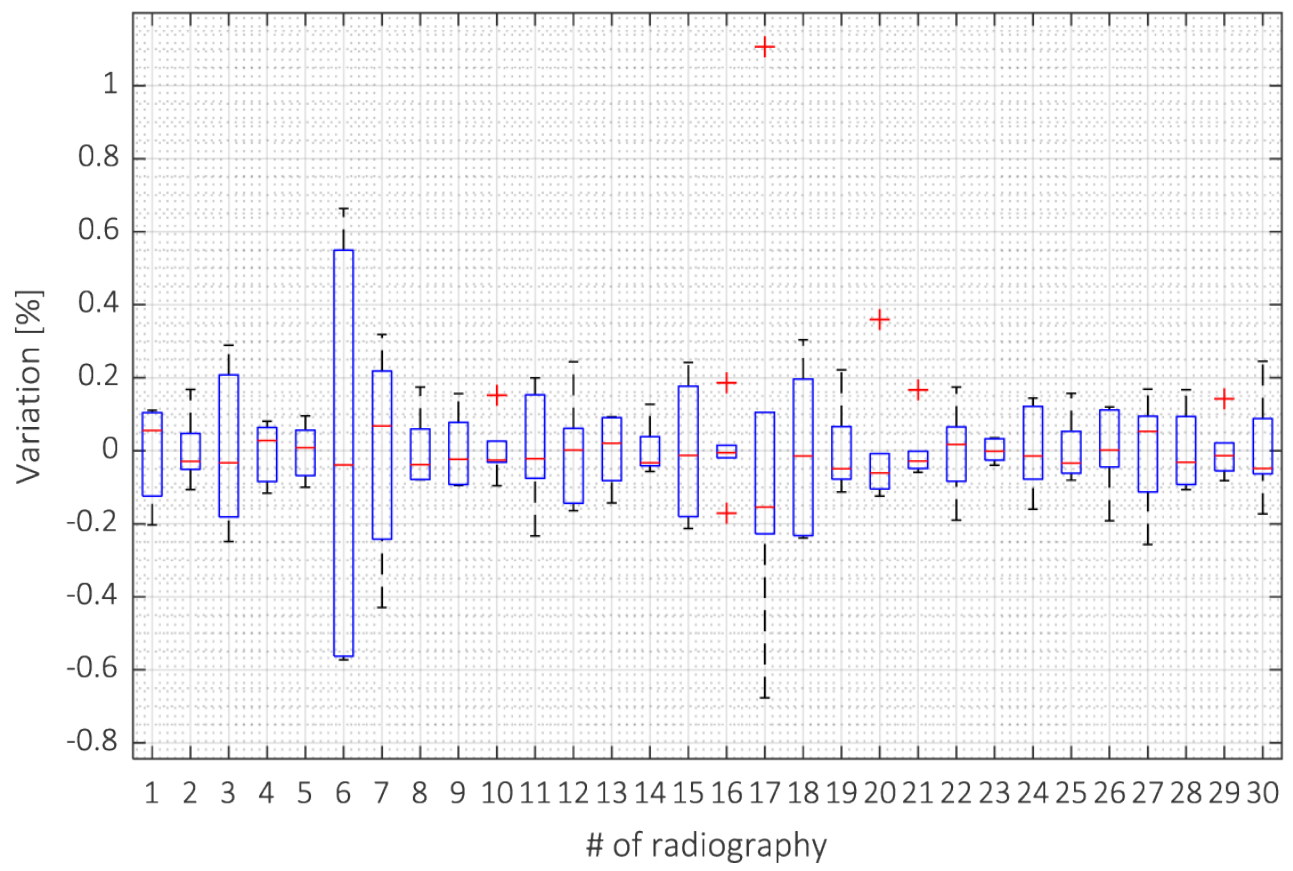

Figure 6: Box plot chart of variation of each radiography using CLT Method.

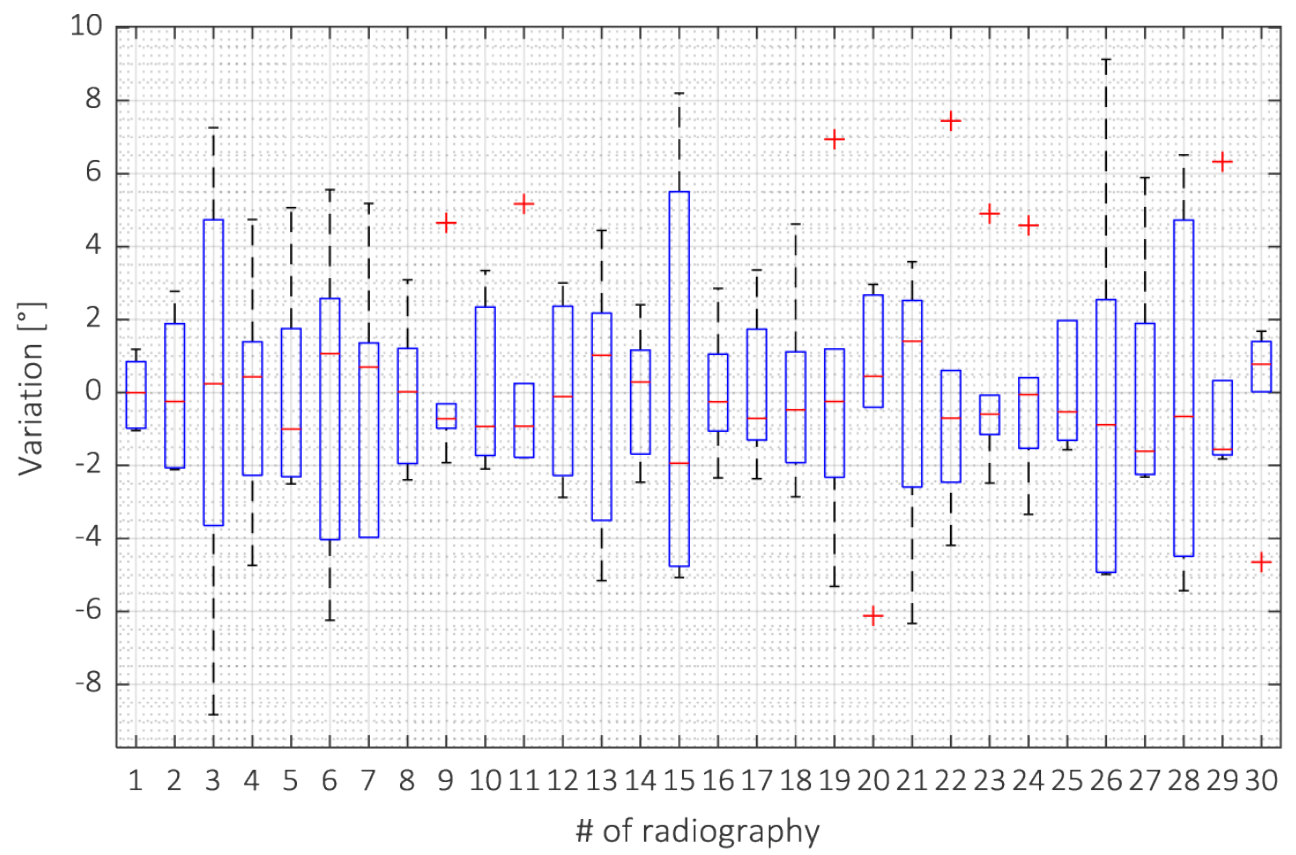

Figure 7: Box plot chart of variation of each radiography using Cobb Method. 


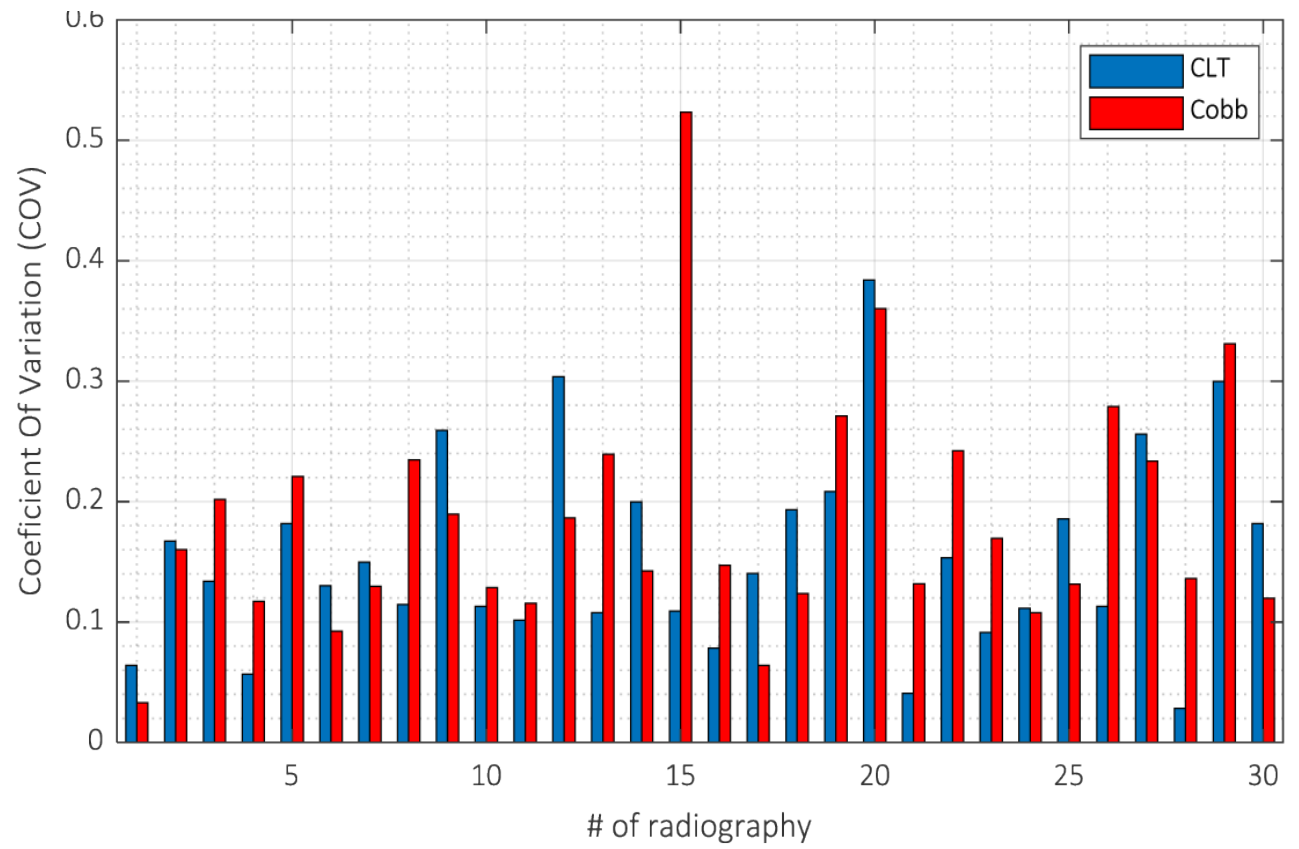

Figure 8: COV of each radiography using CLT and COBB method.

Table 2: Intra-observer measurements by 3 physicians using the Cobb method $(n=30$; unit, ${ }^{\circ}$ ).

Paired Differences

\begin{tabular}{cccccc}
\hline Observer & ICC & Mean & STD & $\mathbf{t}$ & $\mathbf{p}$ \\
\hline $\mathbf{1}$ & 0.863 & -0.91 & 5.20 & -0.95 & 0.348 \\
\hline $\mathbf{2}$ & 0.948 & 1.07 & 3.51 & -1.67 & 0.106 \\
\hline $\mathbf{3}$ & 0.947 & -1.68 & 3.16 & -2.92 & 0.007
\end{tabular}

Table 3: Intra-observer measurements by 3 physicians using the CLT method ( $n=30$; unit, $\%)$.

Paired Differences

\begin{tabular}{cccccc}
\hline Observer & ICC & Mean & STD & $\mathbf{t}$ & $\mathbf{p}$ \\
\hline $\mathbf{1}$ & 0.974 & 0.3 & 0.3 & 1.02 & 0.316 \\
\hline $\mathbf{2}$ & 0.984 & 0.19 & 0.19 & -0.62 & 0.539 \\
\hline $\mathbf{3}$ & 0.979 & 0.23 & 0.23 & 1.55 & 0.133
\end{tabular}

Table 4: Inter-observer measurements by 3 physicians using the Cobb method $(n=30$; unit, ${ }^{\circ}$ ).

Paired Differences

\begin{tabular}{cccccc}
\hline Observer & ICC & Mean & STD & t & p \\
\hline 1 vs 2 & 0.926 & 2.43 & 0.67 & 3.61 & 0.001 \\
\hline 1 vs 3 & 0.935 & 3.01 & 0.62 & 4.85 & 0.000 \\
\hline 2 vs 3 & 0.969 & 0.57 & 0.44 & 1.30 & 0.204
\end{tabular}

Table 5: Inter-observer measurements by 3 physicians using the CLT method ( $n=30$; unit, $\%)$.

Paired Differences

\begin{tabular}{cccccc}
\hline Observer & ICC & Mean & STD & $\mathbf{t}$ & $\mathbf{p}$ \\
\hline 1 vs 2 & 0.986 & 0.010 & 0.219 & 0.241 & 0.81 \\
\hline 1 vs 3 & 0.971 & 0.018 & 0.302 & 0.332 & 0.74 \\
\hline 2 vs 3 & 0.992 & 0.009 & 0.136 & 0.35 & 0.73
\end{tabular}




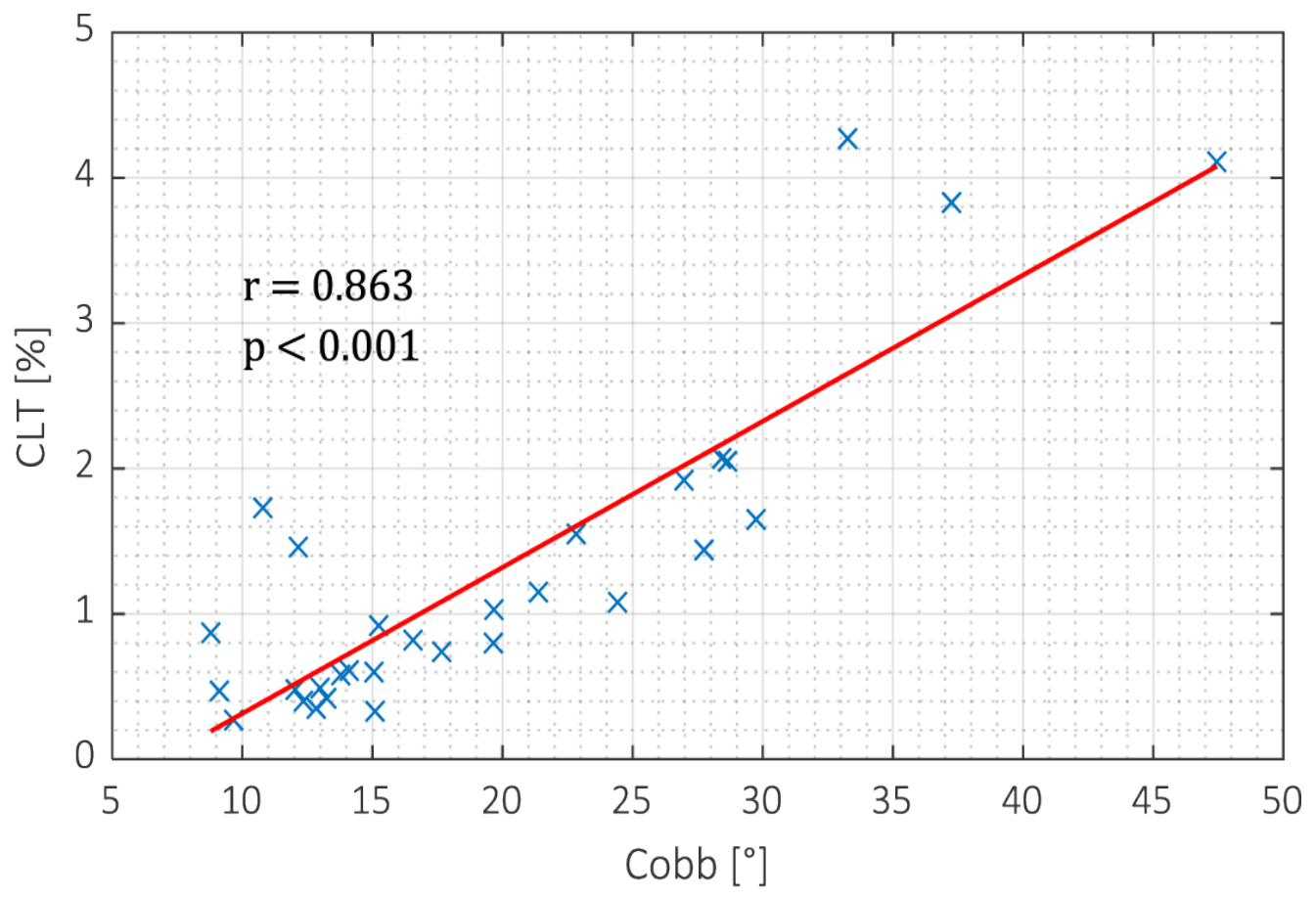

Figure 9: Pearson correlation graph between Cobb and CLT methods $(r=0.863, p<0.001)$.

\section{Discussion}

COV measure, instead of the standard deviation, leads us to compare sets with different units; it can be understood in reproducibility tests shown in Table 1 that measures performed with Cobb method have a COV of 0.185 , which is a larger value than the one achieved by the CLT method of 0.155 . Thus, the CLT method is $16.21 \%$ more reproducible than the Cobb method.

In Jia-Wei [17] work, it is mentioned that the major cause of large variations in measurements using Cobb method is selecting different superior and inferior vertebrae to determine the Cobb angle by observer. Therefore, they proposed the ALDT (Axis-Line Distance Technique) technique. They obtained a Pearson correlation of $0.73(p<0.005)$ comparing with the Cobb method. Since the proposed CLT method achieved a higher correlation of $0.863(p<0.005)$, the CLT method has not only a better relationship with Cobb angle but also less error in comparison with the ALDT technique.

\section{Conclusion}

The use of computer and mathematical tools helps to increase the reliability in each measurement to evaluate the degree of deformity in patients suffering from scoliosis.

CLT method is based on the comparison of the real spine curvature length with an ideal spine length. For that, computer tools are needed such as image processing to emphasize the spine. It manually identifies each centroid of vertebra in order to adjust a polynomial curve.

Between several polynomial curves, the $7^{\text {th }}$ order polynomial achieves a better correlation on average compared with Cobb angle.

\section{Conflict of Interest}

\section{None}




\section{References}

1. Romano M, Minozzi S, Zaina F, Saltikov JB, Chockalingam N, Kotwicki T, et al. Exercises for adolescent idiopathic scoliosis: a Cochrane systematic review. Spine (Phila Pa 1976). 2013;38:E883-93. doi: 10.1097/BRS.0b013e31829459f8. PubMed PMID: 23558442.

2. Qiao J, Liu Z, Xu L, Wu T, Zheng X, Zhu Z, et al. Reliability analysis of a smartphone-aided measurement method for the Cobb angle of scoliosis. J Spinal Disord Tech. 2012;25:E88-92. doi: 10.1097/BSD.0b013e3182463964. PubMed PMID: 22237178.

3. Langensiepen S, Semler 0, Sobottke R, Fricke 0, Franklin J, Schonau E, et al. Measuring procedures to determine the Cobb angle in idiopathic scoliosis: a systematic review. Eur Spine J. 2013;22:236071. doi: 10.1007/s00586-013-2693-9. PubMed PMID: 23443679; PubMed Central PMCID: PMCPMC3886494.

4. Wu W, Liang J, Du Y, Tan X, Xiang X, Wang W, et al. Reliability and reproducibility analysis of the Cobb angle and assessing sagittal plane by computer-assisted and manual measurement tools. BMC Musculoskelet Disord. 2014;15:33. doi: 10.1186/14712474-15-33. PubMed PMID: 24502397; PubMed Central PMCID: PMCPMC3922010.

5. Ritter R, Nagasse Y, Ribeiro I, Yamazato C, Oliveira FMd, Kusabara R. Comparison of Cobb angle measurement in scoliosis by residents and spine experts. Coluna/Columna. 2016;15:13-6. doi: 10.1590/s1808-185120161501147274.

6. Gstoettner M, Sekyra K, Walochnik N, Winter P, Wachter R, Bach CM. Inter- and intraobserver reliability assessment of the Cobb angle: manual versus digital measurement tools. Eur Spine J. 2007;16:1587-92. doi: 10.1007/s00586-0070401-3. PubMed PMID: 17549526; PubMed Central PMCID: PMCPMC2078306.

7. Al-Bashir AK, Al-Abed MA, Amari HK, Al-Rousan FM, Bashmaf OM, Abdulhay EW, et al. Computerbased Cobb angle measurement using deflection points in adolescence idiopathic scoliosis from radiographic images. Neural Computing and Applications. 2019;31:1547-61. doi: 10.1007/s00521018-3614-y.

8. Loder RT, Urquhart A, Steen H, Graziano G,
Hensinger RN, Schlesinger A, et al. Variability in Cobb angle measurements in children with congenital scoliosis. J Bone Joint Surg Br. 1995;77:76870. PubMed PMID: 7559707.

9. Zardo EDA, Ziegler MS, Serdeira A, Severo C, Donazar M, Frast RV, et al. Applicability of the Cobb angle measurement in idiopathic scoliosis using scanned imaging. Coluna/Columna. 2017;16:22-4. doi: 10.1590/s1808-185120171601153058.

10. Kundu R, Chakrabarti A, Lenka P, editors. Automated Cobb Angle Computation from Scoliosis Radiograph. New York: Springer. 2018. p. 140-55. doi:10.1007/978-981-13-1343-1_16.

11. Okashi OA, Du H, Al-Assam H. Automatic spine curvature estimation from $\mathrm{X}$-ray images of a mouse model. Comput Methods Programs Biomed. 2017;140:175-84. doi: 10.1016/j. cmpb.2016.12.010. PubMed PMID: 28254073.

12. Stokes IA, Aronsson DD. Computer-assisted algorithms improve reliability of King classification and Cobb angle measurement of scoliosis. Spine (Phila Pa 1976). 2006;31:665-70. doi: 10.1097/01. brs.0000203708.49972.ab. PubMed PMID: 16540871.

13. Chockalingam N, Dangerfield PH, Giakas G, Cochrane T, Dorgan JC. Computer-assisted Cobb measurement of scoliosis. Eur Spine J. 2002;11:353-7. doi: 10.1007/s00586-002-0386-X. PubMed PMID: 12193997; PubMed Central PMCID: PMCPMC3610477.

14. Lee S, Lee J, Kim J, Kim K, Hwang C, Koo K-i. Precise Cobb Angle Measurement System Based on Spinal Images Merging Function. IRBM. 2018;39:343-52. doi:10.1016/j.irbm.2018.09.002.

15. Greiner KA. Adolescent idiopathic scoliosis: radiologic decision-making. Am Fam Physician. 2002;65:1817-22. PubMed PMID: 12018804.

16. Chen YL, Chen WJ, Chiou WK. An alternative method for measuring scoliosis curvature. Orthopedics. 2007;30:828-31. PubMed PMID: 17990407.

17. He JW, Yan ZH, Liu J, Yu ZK, Wang XY, Bai $\mathrm{GH}$, et al. Accuracy and repeatability of a new method for measuring scoliosis curvature. Spine (Phila Pa 1976). 2009;34:E323-9. doi: 10.1097/BRS.0b013e31819b2504. PubMed PMID: 19531987. 